\begin{tabular}{llll} 
Abstract PTH-023 Table 1 & Endoscopic & investigations \& findings \\
\hline Investigation & $\begin{array}{l}\text { Performed }<1 \\
\text { year before ACS } \\
(\mathrm{n}=113)\end{array}$ & $\begin{array}{l}\text { Performed }<1 \\
\text { year after ACS } \\
(\mathrm{n} n\end{array}$ & $\begin{array}{l}\text { Overall Incidence } \\
\text { of significant } \\
\text { findings }\end{array}$ \\
\hline $\begin{array}{l}\text { Gastroscopy } \\
\text { Lower Gi investigations }\end{array}$ & $10 \%$ & $19 \%$ & $28 \%$ \\
$\begin{array}{l}\text { (Colonoscopy, sigmoidoscopy or } \\
\text { CT pneumocolon) }\end{array}$ & & $17 \%$ & $32 \%$ \\
\hline
\end{tabular}

Only a minority of patients had endoscopic investigations for anaemia (table 1). Significant findings (ulcers, active bleeding or cancer) were found at $28 \%$ gastroscopy more commonly in patients with STEMI (45\%). Significant findings (polpys, cancer, proctitis) were found at 32\% lower GI investigations. No endoscopic complications occurred.

$69 \%$ STEMI and 27\% NSTEMI patients had coronary stenting. $81 \%$ patients were discharged on dual antiplatelet therapy and $16 \%$ on anti-coagulation. 1-year outcome data were available for 99/113. Crude mortality was 24\%. 7.1\% patients developed overt GI bleeding during admission or in the year after ACS.

Conclusions Anaemia is common in patients presenting with ACS. Adequate gastrointestinal investigations were only performed on a minority of these patients but when completed showed a high incidence of iron deficiency and important findings at endoscopy. This patient group has a significant risk of both bleeding and ischaemia and could benefit from complete investigation of their anaemia.

\section{PTH-024 NOVEL CAPSULE ENDOSCOPE WITH 3D RECONSTRUCTION AND LESIONS SIZE CALCULATION: FIRST STUDY WITH MIROCAM MC4000}

Esther Hawkes*, Timothy Keen, Praful Patel, Imdadur Rahman. University Hospital Southampton, NHS Foundation Trust, Southampton, UK

\subsection{6/gutjnl-2019-BSGAbstracts.49}

Introduction Lesions detected at capsule endoscopy currently can only be viewed by a $2 \mathrm{D}$ image and size estimated by subjective image perception. The MiroCam MC4000 uses stereo matching technology to enable reconstruction of selected images in $3 \mathrm{D}$ format to enable size calculation. The aim of this study was to assess the reliability of this novel capsule to reconstruct $3 \mathrm{D}$ images, and its ability to accurately calculate lesion size within a phantom model.

Methods The MC4000 capsule was mounted on a modified plastic shaft with the receiver circuitry system attached. Invitro measurements at various distances were undertaken on a phantom model with static 2D and 3D lesions with sizes between 5-25 mm. In addition, dynamic movements resembling capsule movement through the bowel was performed. The ability to reconstruct images in a $3 \mathrm{D}$ format, in addition to the accuracy of the size calculations within $\pm 10 \%$, was assessed.

Results All lesions within the phantom model were successfully reconstructed in 3D format. For static lesions the MC4000 capsules estimated measurements correlated highly with the known sizes (table 1, 2D lesions).
The effective distance for accurate size measurement for the MC4000 capsule was $10 \mathrm{~mm}$ to $25 \mathrm{~mm}$. In total 2D \& $3 \mathrm{D}$ objects, $5 \mathrm{~mm}$ to $20 \mathrm{~mm}$ in size, were measured with an overall accuracy of $88.4 \%$ within this effective distance.

\begin{tabular}{|c|c|c|c|c|c|c|}
\hline \multirow[b]{2}{*}{$\begin{array}{l}\text { 2D Lesion Size } \\
(\mathrm{mm})\end{array}$} & \multicolumn{5}{|c|}{$\begin{array}{l}\text { Distance between lesion and capsule } \\
(\mathrm{mm})\end{array}$} & \multirow[t]{6}{*}{$\begin{array}{l}\text { Mean } \% \text { error of all } \\
\text { distances }\end{array}$} \\
\hline & 5 & 10 & 15 & 20 & 25 & \\
\hline 5 & 5.73 & 6.28 & 5.82 & 4.65 & 3.29 & \\
\hline 10 & 10.32 & 10.79 & 10.54 & 9.81 & 9.12 & \\
\hline 15 & 15.46 & 16.59 & 16.17 & 15.82 & 14.56 & \\
\hline 20 & $x$ & 19.29 & 18.85 & 17.61 & 16.33 & \\
\hline Mean\% Error & 6.96 & 10.14 & 5.96 & -3.85 & -16.07 & 8.59 \\
\hline
\end{tabular}

There was statistically significant correlation between 2D and $3 \mathrm{D}$ lesion size and measured size for each distance (correlation coefficient $0.98-1, \mathrm{p}<0.049$ ).

Conclusions The MiroCam MC4000 capsule provides reconstructive technology with good size calculations. This novel function may allow more accurate interpretation of lesions identified during capsule endoscopy either for index lesions or when looking for follow up lesion sizes. Further adjustment to the software may be required to bring accuracy to an optimum level to allow further in-vivo studies.

\section{PTH-025 AN ANALYSIS OF FACTORS LEADING TO A DELAY IN DIAGNOSIS OF UPPER GASTROINTESTINAL CANCERS}

B Hayes*, I Bjarnason, B Hayee, P Dubois, G Chung-Faye, R Srirajaskanthan, R Logan, AJ Kent. King's College Hospital, London, UK

\subsection{6/gutjnl-2019-BSGAbstracts.50}

Introduction Delay in diagnosis of Upper Gastrointestinal (UGI) cancer may lead to worse patient outcomes. Several studies have published experience of post endoscopy cancers, with rates ranging between $4.6 \%-21.6 \%$ in Western studies (Mennon and Trudgil, 2014). Our study aimed to identify the incidence of a delay in diagnosis of UGI cancer, investigating the underlying cause, including endoscopic 'misses'. This will identify reversible factors, which may improve our patient outcomes.

Methods A retrospective analysis was undertaken on all patients diagnosed with UGI cancer at King's College Hospital $(\mathrm{KCH})$ between 2011 - 2018 inclusive. Patients who were seen by a gastroenterologist, GI surgeon or had an endoscopy within the last 36 months were screened. Each case was discussed to determine whether a delay had occurred, or a cancer had been missed on endoscopy. Any delay in diagnosis was investigated to identify a root cause.

Results 276 patients were diagnosed with UGI cancer in the time period, with $28(11.3 \%)$ seen in the last 36 months. In 16 of these cases $(5.8 \%)$ a delay in diagnosis was identified (mean 187 days, range - 21-1,106). In 11 cases (4.0\%) the delay was less than 12 months. The factor leading to a delay in diagnosis were: post-endoscopy cancer $(n=10)$, inadequate investigation $(n=3)$ and delayed investigation $(n=3)$. The missed cancer rate 